\title{
An Educational Model for Asynchronous E-Learning. A case study in Higher Technology Education

\author{
doi:10.3991/ijac.v3i1.987
}

\author{
D. Papachristos ${ }^{1}$, N. Alafodimos ${ }^{1}$, K. Arvanitis ${ }^{2}$, K. Vassilakis $^{3}$, M. Kalogiannakis ${ }^{4}$, P. Kikilias ${ }^{1}$, E. Zafeiri ${ }^{1}$ \\ ${ }^{1}$ TEI of Piraeus, Piraeus, Greece \\ ${ }^{2}$ Agricultural University of Athens, Athens, Greece \\ ${ }^{3}$ Technological Educational Institute of Crete, Crete, Greece \\ ${ }^{4}$ University of Crete, Crete, Greece
}

\begin{abstract}
Nowadays, the use of Web based Education (WbE) in distance learning education is considered to be an innovative method of learning. Supporters argue that $\mathrm{WbE}$ renews educational practices through the use of computers and their applied methodology, as well as the technologies provided by the use of the internet. By consciously renewing the educational material the creation of a flexible structure is achieved, which promotes the individualization of learning. In this article we study a WbE application and propose a model that aims at delivering online technological classes, offering a flexible use of means and tools. Additionally, this model allows a synthesis of selected bibliography that covers the issue cognitively, develops cooperative spirit and individualise the learning procedure.
\end{abstract}

Index Terms-Web Based Education, Asynchronous Distance learning, Higher Technology Education.

\section{INTRODUCTION - THEAORATICAL FRAMEWORK}

The flexibility in distance education has been put forth as an example of how citizens will be given larger possibilities to study and educate themselves. Open and Distant Learning (ODL), provides new opportunities for teaching and learning and a sufficient variety of digitalbased means for both students and teachers. In ODL platforms, students must be at the centre of their own learning (student-based learning) and these systems must be well designed to facilitate learning process.

ODL offers new educational environments, where anyone can learn anytime anyplace and get quality education. In ODL the instruction could be either "synchronous", meaning that the communication between teacher and learner is simultaneous, or "asynchronous" which means that the student is able to interact at any time, without teacher's presence. The ODL instruction could also be based on a mixture of the above two modes.

There are quite a few pedagogic models and learning instructive theories. The most popular of them are the following [1], [6], [16], [22], [25]:

The Behaviouristic model is based on the idea that the learning procedure is a form of observed behavior and the outcome of a response to some kind of stimulus (Stimulus $\rightarrow$ Reaction).
The Cognitive approach model. This model focuses on the internal cognitive processes performed within the students' mind during the learning procedure.

The model of Constructivism. Within this model the students should have or acquire the ability of managing the applied learning procedure. As a result, the learning procedure is driven by and evolved through the social interaction during lectures. The teacher creates and uses this type of knowledge attained by actions adjusted to the class delivery content.

Models of established learning and learning communities. This model is based upon two principles: firstly, the facts that knowledge can be found and acquired within an authentic environment-framework, so students attain knowledge through empirical circumstances. The second principle lies on the presumption that new knowledge and learning can be found within social communities and therefore social interaction and teamwork cooperation are considered to be of significant importance.

By comparing the most recent pedagogical models, as studied by Merrill (2002), it appears that the most effective learning environments are those focusing on problem solving (problem-centered) and considering that there are distinctive phases within the learning procedure. Furthermore, Merrill suggests the following "Basic Teaching Principles" (Figure 1), according to which, the learning procedure is promoted when: (a) students focus on solving substantial problems, (b) students' previous experience and knowledge are activated and used as the basis for new knowledge, (c) new knowledge and skills are presented to the students, (d) new knowledge and skills are applied by the students, and (e) attained knowledge and skills are incorporated to the students' learning environment.

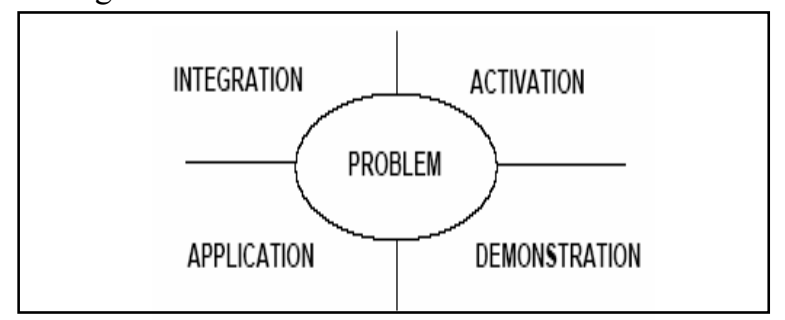

Figure 1. Merrill's basic teaching principles 
It must be noted that according to Merrill's analysis learning is promoted when the instruction demonstrates what is to be learned, rather than merely giving information about what is to be learned, when learners (a) are required to use their new knowledge or skill to solve problems and (b) are encouraged to integrate the new knowledge or skill into their everyday life. In other words, students as individuals attain knowledge rather than participating to an educational group [12]. However, there are several other pedagogical models explicitly focusing on learning, practice and collaboration communities [18], [21], [24]. In addition, there is a new predisposition towards more social-constructivism learning approaches embraced by the educational community [5], [7].

According to Bransford, Brown and Cocking, (2000) the educational procedure must focus on students assessment, the learning material and the learning community [4]. The information, data and facts provided can be rather effected and interpreted, when the social framework is reconstructed through the learning procedure [11]. Nowadays, the non-linear model, mostly based on the model of constructivism, is widely used in designing educational systems [3], [10], [17], [19], [22], [23].

Based on the above theoretical framework we develop a schema for asynchronous distance teaching technological courses, using web based infrastructures (WbE). Technological courses have particular teaching demands especially for the laboratorial practice. The proposed educational model uses contemporary trends in educational and consists of two sectors: the theoretical and the laboratorial.

\section{EDUCATIONAL MODEL}

The proposed model concerns the teaching of technological cognitive modules. The technological class or teaching material includes not only theory and servile work, but also concretisation skills that presuppose the use of all senses. In addition, the process of learning in such a cognitive environment cannot involve simple activities, such as memorization, rationalisation and rethinking. It should also include more composite processes, such as creation, experimentation and feedback. An educational model consists of two components (a) the learning frame and (b) the teaching frames. Therefore the stages of creation of the $\mathrm{WbE}$ model are clearly illustrated in the following diagram (Figure 2):

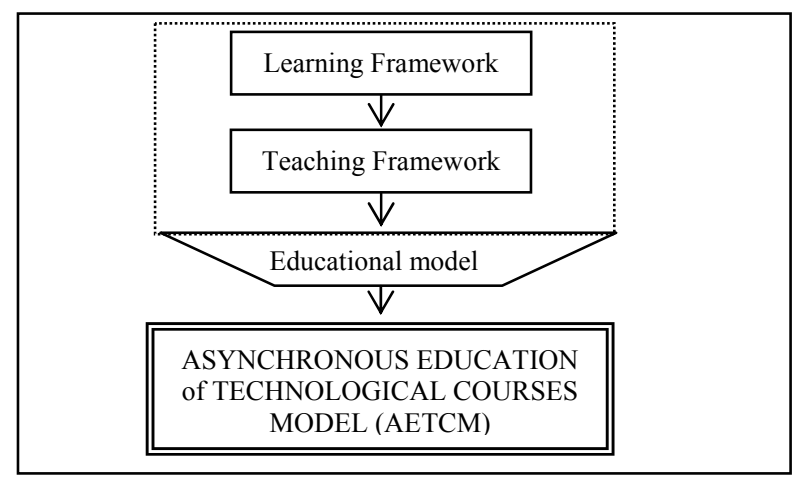

Figure 2. Stages of the creation of the educational model for WBE
To implement the WbE model, an infrastructure should be developed according to model's specifications in order to host the technological courses (Asynchronous Education of Technological Courses System - AETCS).

The proposed model has the following characteristics:

Educational Material. In cases of asynchronous distance teaching as $\mathrm{WbE}$, the material does not depend only on a single textbook, but on many resources in different content forms including: course material, bibliographic sources and self-assessment material [8].

Tools. The model uses in digital form educational software and tools as well, to develop, present and distribute educational material on line in various types (text, pictures, animation and video).

Educational Methods. In each course various educational methods are applied according to the requirements of asynchronous education, which comprise the base of the instructive framework of the proposed model. More specifically, depending on the subject of each course, the following means are used: lecture (text, forms, pictures and sound), demonstration (video, animation), individual work (email), group work (email, forums, chatting), discussion with the instructor (via email or on the phone) and assessment.

Time of Education. At the beginning of each course an overall course time load is suggested to the students. The allocated time varies for each course depending on the content that includes studies, practice, and assessment. This time is not obligatory for the students and it can be increased or decreased depending on the rhythm of learning (asynchronous use of the proposed model). However, it should not exceed a concrete time limit that is set by the teacher for the overall assessment of the course.

Learning Theories. Each course is conditioned according to the training frame of the proposed model. More specifically, the model of cognitive approach and the constructive process of teaching material based on Blooms theory are applied in the content of the educational material [22]. Furthermore, students' cooperation via group or project work is promoted during the instructive process.

\section{MODEL STRUCTURE}

For the design of the Asynchronous Education of Technological Courses Model (AETCM) elements of relevant published theoretical models for asynchronous education were used [7], [19], [21]. The offered courses will function as completely autonomous parts in the course's web site (AETCS), so that each learner can take up the course without attending the corresponding conventional class.

The AETCM consists of two sectors: the theoretical sector that includes the theory and the laboratorial sector that includes the hands-on (practical) education of the technological course. For the design of the course, elements from relevant models of asynchronous education were used including [2], [8], [9] [12], [14], [15].

AETCM's general structure is outlined in the following diagram (Figure 3): 


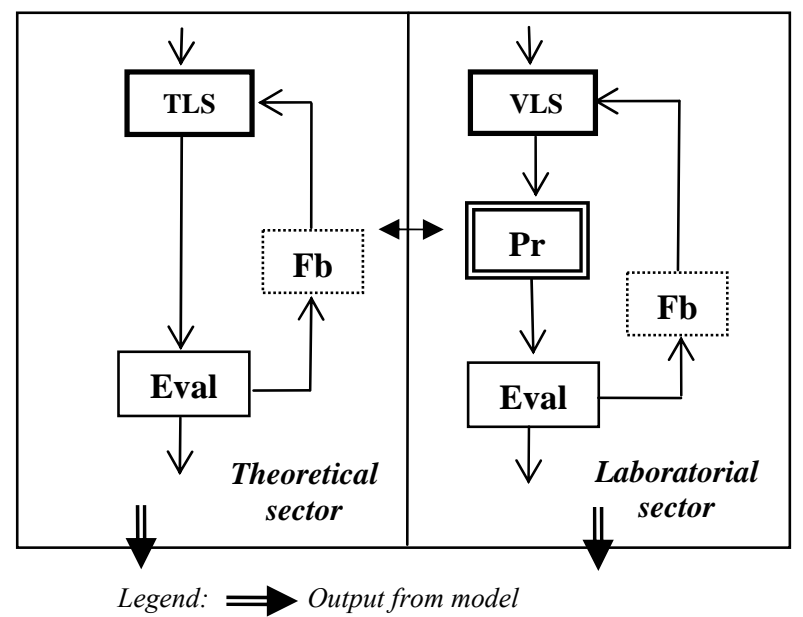

Figure 3. AETCM structure. TLS: Teaching Learning Section, VLS: Virtual Lab Section, Pr: Practice, Fb: Feedback, Eval: Evaluation.

The Teaching Learning Section consists of three educational levels:

Basic infrastructure level - BIL (obligatory, when failing the diagnostic test). This level is obligatory for those who lack adequate knowledge. Therefore, it provides educational material properly organized in progressive and linear structure, to cover the gaps of knowledge.

Educational level - EL (obligatory). It consists of courses in linear order. These courses are mandatory for all students, since they provide the necessary educational material of the technological course. Each course is divided in thematic educational units presented sequentially. The student should complete the previous unit in order to continue to the next one (typical procedure). At the end of each course the students are assessed.

Specialisation level - SL (optional). This level is addressed to students who wish to broaden their knowledge, provided that their teachers advise them to do so. Educational material structured in units with detailed analysis and exercises is provided. Also, tutorial courses are offered to enhance analysis and look into case studies.

The structure of Teaching Learning Section (TLS) is illustrated in Figure 4.

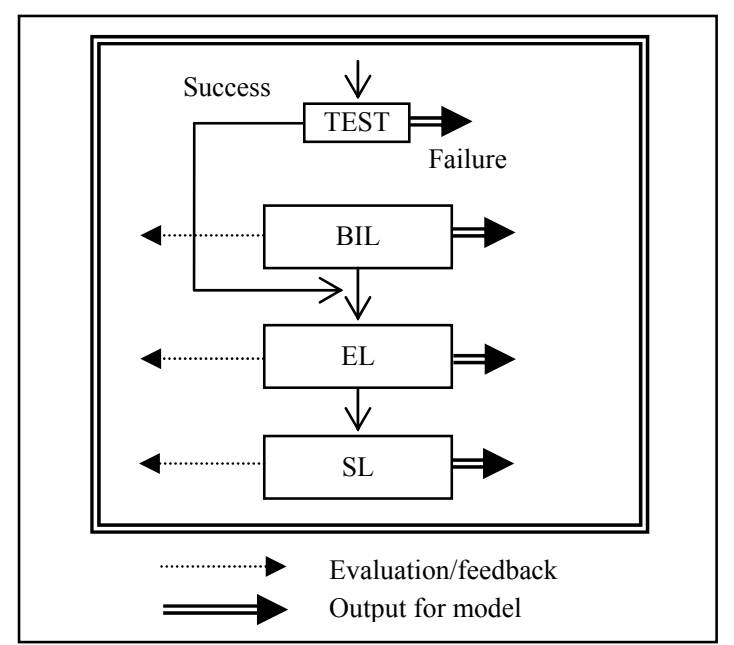

Figure 4. TLS structure. BIL: Basic Infrastructure Level, EL: Educational Level, SL: Specialisation Level
At the end of each level an obligatory final test is conducted.

The Virtual Lab Section is suggested to have the following structure (Figure 5):

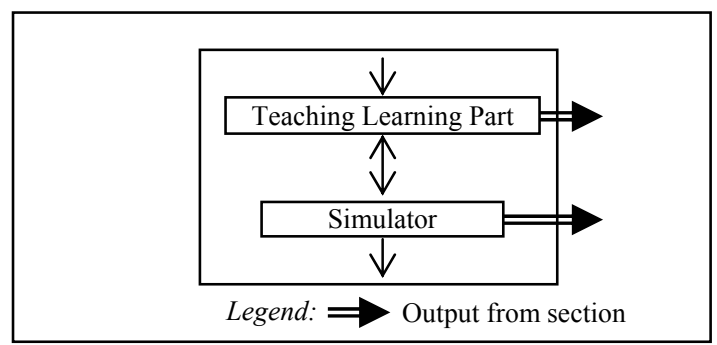

Figure 5. Virtual Lab structure

Teaching-Learning Part (TLP) has the same structure as the TLS in the theoretical sector. In Simulator part laboratorial educational software for simulation is provided for laboratorial practice in digital environment.

The Practice Section provides scripts of laboratorial exercises for Simulator Use by the students.

The Evaluation Section has the same structure for both Teaching-Leaning and Virtual Lab sections (TLS \&VLS) as it appears in the following figure (Figure 6):

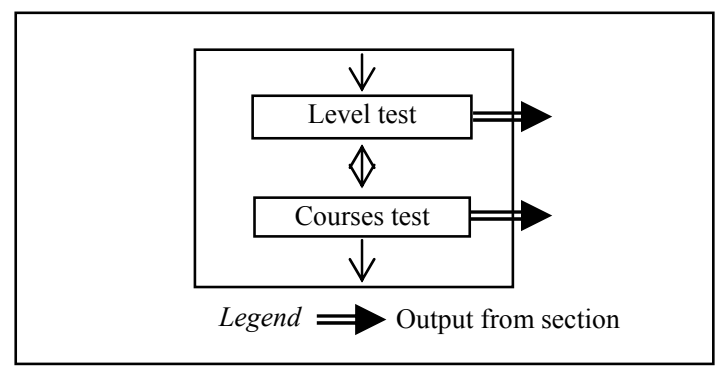

Figure 6. Structure of Evaluation dept

The assessment of the students is conducted through courses tests and level test. The former is based on the courses material, whereas the latter assesses the material of the level overall.

Feedback Section deals with the communication between the instructor and the students. It has the form of partial bidirectional communication and serves the following: (a) transfer of assessment tests and results, (b) transfer of questions, comments regarding the course, (c) evaluation of the system from the students and (d) depiction of educational directives in a forum by the teacher. The data above is transferred by e-mail via internet.

The structure of Feedback Section is illustrated in Figure 7 and it is the same for both sectors:

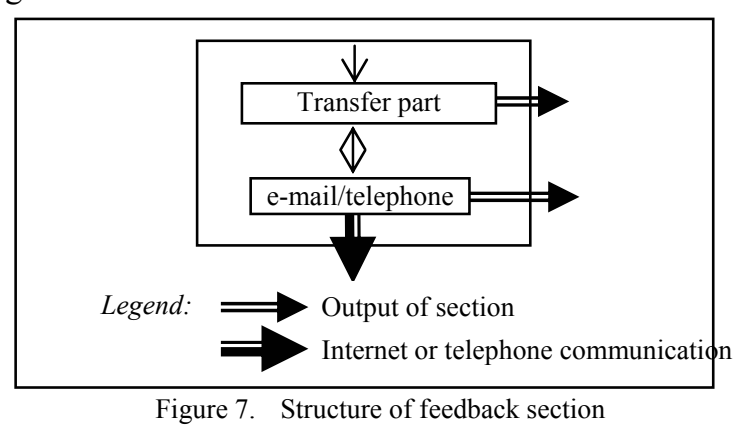

Figure 7. Structure of feedback section 
Transfer part deals with the collection of evaluation forms, texts with comments, indications, additional educational material from the teacher (it can be done electronically). The part of email/telephone deals with the online communication between the instructor and students.

\section{CASE STUDY}

The proposed example of model materialization was used in higher Technological Educational Level and involves the teaching of a cognitive technological module. Teaching can take place either in a real class assisted with online supporting material, or exclusively remotely through the internet.

More specifically, a course in Computer Numerical Controls (CNC) is offered online by the department of Automation of the Technological Educational Institute of Piraeus. The course is offered in the $7^{\text {th }}$ semester and has both theoretical and laboratorial parts. The course includes an introduction to machine-tools of numerical control using a computer. The cognitive subject of the course is very useful in industry in the area of flexible manufacturing automated systems.

The theoretical sector of the course deals with operational principles, design, control and applications of machine-tools CNC. The laboratorial sector deals with the planning of such machine-tools with the use of a simulator. The simulator used is the SYBA-CNC for lathing and milling. Unlike most asynchronous infrastructures that usually offer predefined development environments, technological teaching deals most with fieldwork and rehearsal and it is based on specific tools (e.g. simulator). The implementation of the model can be done in any programming environment for the creation of web pages (e.g. MS Frontpage). For the production of educational material the various information technology tools can be used such as MS-Office, OpenOffice, Flashmedia, Video processing software, Photoshop, Director, CoolEdit, 3D Max etc.

The technical resources used for the materialization of the AETCS and the overall structure of the system are given in the following diagram (Figure 8).

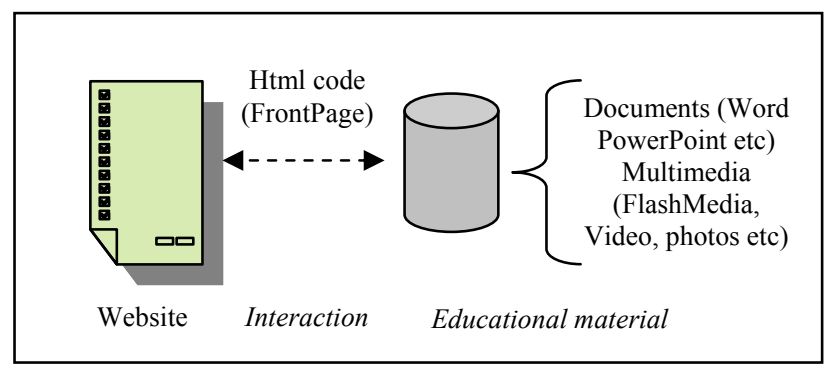

Figure 8. Technical resources of application

The architectural structure of the application is based on the proposed model and the contents are presented hierarchically according to model's specifications. Each course includes theoretical and laboratorial sectors and practice, feedback and evaluation sections. Additionally there are sections for instructions, system's usage and navigation demos. The architecture of the pilot application is illustrated in Figure 9.

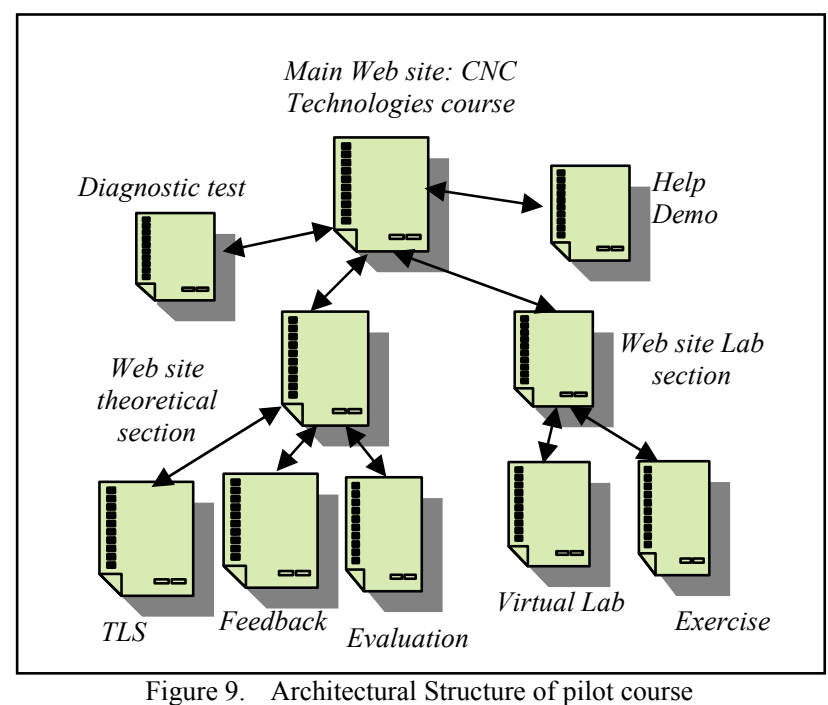

The storyboard navigation in the pilot case study is both ways interactive. It is very similar to an electronic book enriched with advanced multimedia content such as: pictures, sound, text and video.

The design of the interface takes into account easy navigation and ergonomic usage. It can be implemented using any web design software tool. More specifically it offers:

- simplicity,

- clarity,

- proportional dimensions

- proper hierarchy and

- balance.

The text in the web pages:

- offers good readability,

- uses legends with different color and bold writing,

- has black color in main text,

- uses bold, italic and color in keywords,

- uses tables and

- includes multimedia content.

The design of the pilot interface is illustrated in the following figure (Figure 10):

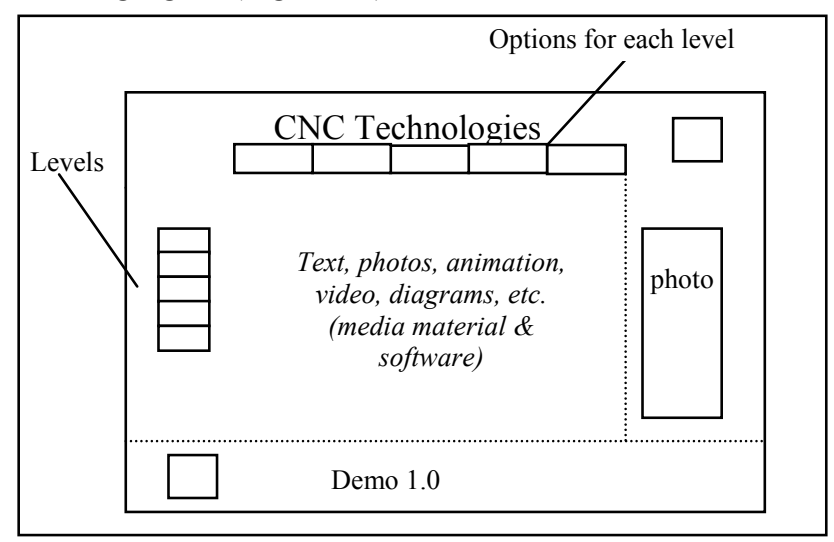

Figure 10. Structure's interface of model. 


\section{CONCLUSION}

The integration of information and telecommunication technologies has promoted distance learning by providing learning environments that are accessible to individuals at any time and any place. The issue of facilitating people to "learn how to learn" has been an active research area, and now there is a growing acceptance of the fact that understanding the way students learn is the key to improve the educational process.

Within the last few years, e-learning has changed not only the technology of the educational environment, but also the educational paradigm itself. The advantages of elearning are twofold: (a) both teachers and students can overcome time and space restrictions, and (b) the students can study individually and cooperatively in parallel. Consequently, e-learning systems have to be designed in a way to cope with different learning styles and students' goals and learning rhythm offering user profiles.

The proposed educational model and its concretisation system will focus on a learning style trying to promote flexibility, cooperativeness and individualization. Furthermore, a specialized environment of technological cognitive subjects will be offered, which plays an important role in distance and asynchronous learning. The main objective of the designers is the completion of this model, the further development of the concretisation system and its evaluation in factual action.

Online collaborative learning extends teaching beyond the classroom and provides individual learning. It creates relationships between students, which promote their learning through collaborative educational environments and their own learning pace.

\section{REFERENCES}

[1] Anderson, J.R., Reder, L.M. \& Simon, H.A. (1996). "Situated Learning and Education", Education Researcher, 25(4), pp. 5-11.

[2] Arvanitis, C., Papachristos, D., Koronaios, N. (2005). N., "Educational model self e-learning in e-commerce for residents of mountainous or faraway regions", Proceedings of the Greek Conference for Lifelong Learning, 16-17 April, 2005, Lamia.

[3] Blumer, H. (1969). "Symbolic Interactionism: Perspective and Method", NJ: Prentice Hall

[4] Bransford, J., Brown, A. L. \& Cocking, R. R. (2000). "How People Learn: Brain, Mind, Experience, and School" (expanded edition), Washington: National Academy Press.

[5] Brown, J. S. \& Duguid, P. (2000). "The Social Life of Information", USA: Harvard University Press.

[6] Cobb, P., Wood, T. \& Yakel, E. (1990). "Classroom as learning environments for teachers and researchers", In Von Glasersfeld (ed.), Radical Constructivism in Mathematics Education, NL: Kluwer, pp. 157-176.

[7] Duffy, Th.M. \& Cunningham, D.J. (1996). "Constructivism: implications for the design and delivery of instruction", In D.H. Jonassen (Ed.), Handbook of Research for Educational Communications and Technology. New York: Macmillan.

[8] Holmberg, B. (2001). "Theory and practice of distance education,", London: Routledge.

[9] Karagiannis, St., Karachisaridis, E., Papachristos, D. (1996). "Multimedia Application in Robotics teaching", Conference Proceedings Technology and Automation, TEI Piraeus, May 1996.

[10] Kuhn, T. S. (1996). "The Structure of Scientific Revolutions", USA: The University of Chicago Press.

[11] Lave, J., \& Wenger, E. (1991). Situated learning: legitimate peripheral participation, Cambridge: Cambridge University Press.

[12] Merrill, M.D. (2002). "First Principles of Instruction", Educational Technology Research \& Development, 50(3), pp. 4359. (doi:10.1007/BF02505024)

[13] Papachristos, D., Tsoukalas, V., Alafodimos, C., Tselenti, N., Mattheu, L. (2007). "Educational Model of the Merchant Marine engineers' continuous education with the use of asynchronous distance education", Proceedings of CBLIS 2007, TEI of Crete, June, 2007.

[14] Papachristos, D., Kalogiannakis, M., Patelis, G., Roditou, S., Tsoukalas, V. (2009) "An Educational Model for E-Learning- A Case Study" in E-Commerce, International Journal of Electronic Trade (IJETrade) (under publication).

[15] Patelis, G., Papachristos, D., Kalogiannakis, M., (2006). "ELearning educational model of $\mathrm{C}++$ programming languages", Greek Conference Digital Educational Material: Subjects, educational creation and evaluation, University of Thessalia, Abstract Papers, April 7, 2006, Volos-Greece.

[16] Perkins, D. N. (1992). "What constructivism demands of the learner", Duffy, T.M. \& Jonassen D.H. (eds.), Constructivism and the technology of instructions, NJ: Lawrence Erlbaum Associates, pp. 161-166.

[17] Piaget, J. (1970). "Genetic Epistemology”, NY: Columbia University Press.

[18] Retallick, J., Cocklin, B. \& Combe, K. (1999). "Learning Communities in Education", London: Routledge.

[19] Retalis, S., (2005). "Internet Advanced Technologies in learning services", Athens: Kastaniotis.

[20] Tennant, M. (1997). "Psychology and Adult Learning”, UK: Routledge.

[21] Van den Hooff, B., Elving, W., Meeuwsen, J. M. \& Dumoulin, C. (2003) "Knowledge Sharing in Knowledge Communities". In M. Huysman, E. Wenger \& V. Wulf (Eds.), "Communities and Technologies". Dordrecht: Kluwer Academic Publishers.

[22] Von Glaserfeld, E. (1989). "Cognition, construction of Knowledge, and teaching", Synthese, 80(1), pp. 121-140. (doi:10.1007/BF00869951)

[23] Vygotsky, L. (1978). "Mind in Society”, MA: Harvard University Press.

[24] Wenger, E. (1998). “Communities of Practice: Learning, Meaning and Identity”, New York: Cambridge University Press.

[25] Wertsch, J. V. (1985). "Vygotsky and the Social Formation of Mind", USA: Harvard University Press.

\section{AUTHORS}

D. Papachristos, is a Technical and Laboratory assistant at the Technological Educational Institute of Piraeus (School of Engineering, Department of Automation Engineering) in Aigaleo, PO 122 44, Greece (dimitriospap@mail.gr).

N. Alafodimos, is a Laboratory researcher at the Technological Educational Institute of Piraeus (School of Engineering, Department of Automation Engineering) in Aigaleo, PO 122 44, Greece (nalafod@teipir.gr).

K. Arvanitis, is an Associate Professor at the Department of Natural Resources Management and Agricultural Engineering, Agricultural University of Athens, PO 118 55, Athens, Greece (karvan@aua.gr).

K. Vassilakis, is currently associate professor at the Technological Educational Institute of Crete (Science Department/Computer Science Division) in Heraklion, Crete, PO 1939, Heraklion-Greece (email: K.Vassilakis@teicrete.gr).

M. Kalogiannakis, is a lecturer at the Department of Pre-school Education in the University of Crete, PO 74100, Rethymno-Crete, Greece (mkalogian@edc.uoc.gr).

P. Kikilias, is an Emeritus Professor in the Technological Educational Institute of Piraeus Aigaleo, PO 122 44, Greece (pkik@teipir.gr).

E. Zafeiri is a Secondary School English Teacher, currently working as a researcher in the Centre of Technological Research of the Technological Educational Institute of Piraeus Aigaleo, PO 122 44, Greece (email: evizafiri@yahoo.gr).

Submitted June 30, 2009. Published as resubmitted by the authors February $2^{\text {nd }}, 2010$. 